\title{
PAIKANTUMISIA QUEER-TUTKIMUKSEN KÄSITTEISIIN JA HISTORIAAN
}

\author{
Salla Aldrin Salskov, Leena-Maija Rossi ja Riikka Taavetti
}

Suomen Queer-tutkimuksen Seuran lehden kaksoisnumero vuodelle 2019 paneutuu queer-historiaan ja -käsitteisiin. Kutsuimme avoimella kirjoituskutsulla tutkijoita ja muita kirjoittajia pohtimaan queer-teoriaan ja -tutkimukseen liittyviä käsitteitä, queer-historiaa, käsitteiden historiaa sekä queer-teorian paikantumista. Kutsuumme vastattiin runsain mitoin, niinpä luettavananne on kaksoisnumero, jossa on kolmen tutkimusartikkelin lisäksi myös esseitä, keskusteluihin pohjautuvia tekstejä, kirja-arvioita ja jopa elokuvaesittely.

Queer-teorialla on oma, hyvin vahvasti paikallistunut historiansa angloamerikkalaisen seksuaali- ja sukupuolivähemmistöjen sekä feministien aktivismin ja tutkimuksen leikkauspisteissä 1980-luvun lopussa ja 1990-luvun alussa (ks. esim. de Lauretis 1991; Rossi 2017; Kornak 2015). Kun queer viimeisten kolmenkymmenen vuoden kuluessa on levinnyt akateemisena ja poliittisena käsitteenä huomattavasti syntykontekstiaan laajemmalle, tutkijat ovat keskustelleet sen sovittamisesta sellaisiin yhteiskunnallisiin ja historiallisiin olosuhteisiin, jotka ovat varsin erilaisia kuin angloamerikkalaiset. Niinpä queer-käsitteen sovittamisesta ja kääntämisestä eri konteksteihin on keskusteltu laajasti englanninkielisen maailman ulkopuolella (ks. esim. Mizielińska \& Kulpa 2011 queer-käsitteen sovel- tamisesta itäisen Keski-Euroopan yhteiskuntiin, Suomesta myös esim. Mizielińska 2006).

Siinä missä esimerkiksi Norjassa queer-käsitteen käännöksenä on käytetty paikallista skeivt-käsitettä (esim. Hellesund 2016), Suomessa queer jätetään useimmiten kääntämättä, vaikka lukuisia erilaisia käännöksiä on ehdotettu; näistä mainittakoon kumma- ja outo- sanat ja niiden johdannaiset, sekä vikuuri ja pervo (ks. esim. Rossi 2003; Kekki 2006; Vänskä 2006). Viimeinen vaihtoehdoista, pervo, on alusta saakka jäsentänyt tämänkin julkaisun osastoja "Pervoskooppi"-artikkeliosiosta "Pervosilmäys"arvosteluihin. Lehden nimessä esiintyy kuitenkin queer, samoin kuin Suomen Queer-tutkimuksen Seuran nimessä. Queer-käsitteen houkutus lienee osin siinä, ettei sillä ole vieraskielisyytensä vuoksi suomen kielessä queer-teoriaa edeltävää käyttöä eikä aiemman historian painolastia. Toisaalta sillä ei tästä johtuen ole suomen kielessä myöskään samanlaista vahvaa yhteyttä epänormatiiviseen, kummeksuttuun ja vinona pidettyyn seksuaalisuuteen. Juuri näitä yhteyksiä on haettu eri käännösehdotuksissa, joissa heijastuu myös queer-teorian ja käsitteen eri tulkintoja, painotuksia ja käyttömahdollisuuksia, ajan ja paikantumisen merkityksiä. 


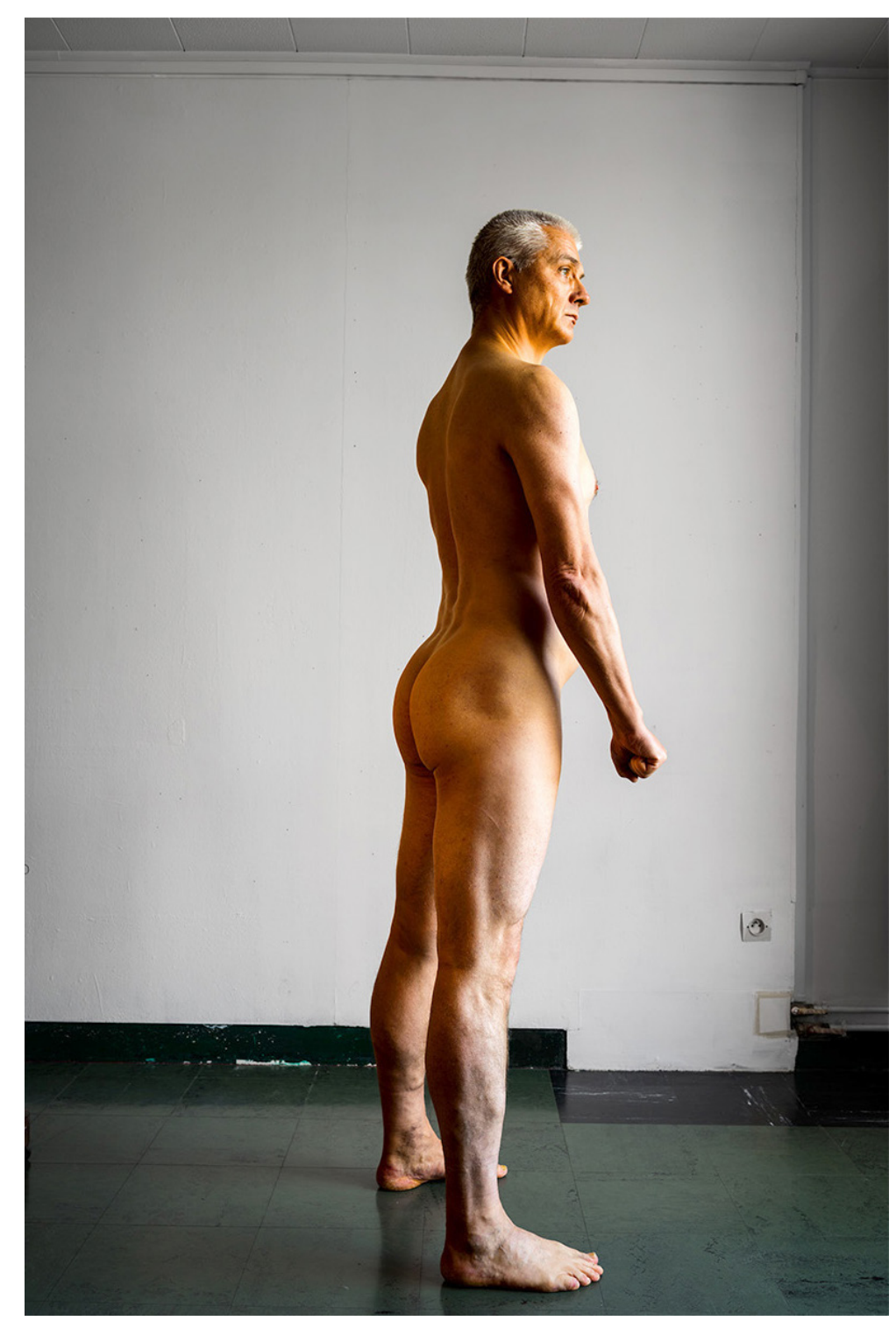

KUVA: Kari Soinio, Jean d'Aire, Calais'n porvarit (Après de Rodin) / 2018 (Les Bourgeois de Calais, Auguste Rodin, 1884-1889).
SQS on ollut alusta saakka kolmikielinen lehti, joka julkaisee artikkeleita suomeksi, ruotsiksi ja englanniksi. Pidämme tärkeänä niin kotimaisilla kielillä julkaisemista kuin avoimuutta ulkomaisille tutkijoille sekä sellaisille Suomessa toimiville tutkijoille, joiden kirjoituskieli ei ole suomi tai ruotsi. Queer-kielen mahdollisuuksia tai kielen queeriyttämistä pohditaan tässä numerossa erityisesti Sini-Petriina Klaston kirjoittamassa keskustelutekstissä ohjaaja Mikko Mäkelän kanssa. Teksti liikkuu kielellisesti suomen ja englannin välissä ja pohtii suomalaista queer-diasporaa sekä suomalaisuudelle annettuja merkityksiä Suomen ulkopuolella.

Kuten Klaston ja Mäkelän keskusteluteksti jo osoittaa, tässä numerossa käsitteitä ja historiaa ei käsitellä vain perinteisen tieteellisen kirjoittamisen tyylilajissa, ja erityisesti esseissä on käytetty mahdollisuutta myös henkilökohtaisempaan kirjoittamiseen. Joonas Säntti pohtii omassa esseessään sukupuolettomuuden ja määrittelemättömän sukupuolen tarjoamia lukumahdollisuuksia suomalaisessa nykykirjallisuudessa. Säntti valottaa myös sitä miten queer voi haastaa käsityksiä queeristä, jos käsitteestä tulee valheellisen kattava ja sitä, millaisiin sukupuoli- ja seksuaalinormien ylityksiin tai venytyksiin käsite voi ulottua ja millaisia tulkintoja queer teoriana ja kehyksenä mahdollistaa. Tiina Männistö-Funk puolestaan jäljittää esseessään ristiinpukeutumisen mahdollisuuksia ja sen saamia merkityksiä eri aikoina ja eri paikoissa. Männistö-Funk nostaa esiin myös harvemmin analysoituja queer-mahdollisuuksia maaseudulla, kaukana queer-historian tutummasta kontekstista, suurkaupungeista, sekä pohtii luokan ja sukupuolirajan ylitysten risteämiä.

Numeron toinen keskusteluartikkeli on Johanna Pakkasen, RoseMarie Peaken ja Outi Santavuoren vuoropuhelu kahdesta elämäntarinakokoelmasta, vuonna 1992 ilmestyneestä Toisenlaisia naisia -kirjasta sekä tuoreesta, vuonna 2019 julkaistusta teoksesta Entiset heterot: Kuinka löysin itseni sateenkaaren alta. Kirjoihin kerätyistä elämäntarinoista löytyy

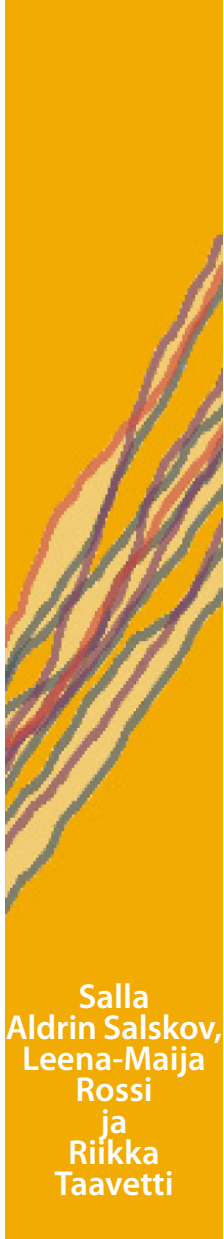


edelleen samanlaisuutta huolimatta lähes kolmen vuosikymmenen ajallisesta etäisyydestä ja yhteiskunnallisesta muutoksesta koskien sukupuolen ja seksuaalisuuden merkityksiä varsinkin lainsäädännön tasolla. Kirjoittajat pohtivat myös akateemisen queer-tutkimuksellisen keskustelun sekä omaelämäkerrallisen kerronnan risteyksiä ja mahdollisia hankauskohtia.

Omaelämäkerrallisen kerronnan queer-luenta on kohteena myös yhdessä teemanumeron kolmesta vertaisarvioidusta artikkelista. Tuula Juvonen käsittelee artikkelissaan nimeämiseen ja identiteettiin liittyviä kysymyksiä tuoreessa Unohtumattomat hetket -muistitietokeruussa (2018, Työväen muistitietotoimikunta), jonka tavoitteena oli erityisesti queer-elämää kuvaavien muistojen kerääminen. Juvosen analyysi valottaa, millaisia uudenlaisia paikantumisia identiteettiterminologian kasvu ja leviäminen on viime vuosikymmeninä synnyttänyt ja mahdollistanut. Teoreettisena näkökulmana artikkelissa on suhteisuus: niin sukupuolen kuin seksuaalisuuden nimeäminen ymmärretään aina jollain tapaa relationaalisena, suhteessa muihin.

Marianne Liljeström taas pohtii artikkelissaan spesifisti tutkimuksellisia paikantumisia, ja paneutuu myös suhteisiin: tarkemmin queer- ja feministisen teorian yhteyksiin, näitä suhteita tarkastelleissa keskustelussa syntyneisiin ajallisiin jatkumoihin ja kertomuksiin queer-teorian merkityksistä. Fokuksessa feministisen ja queer-ajattelun historiallisten yhteenkietoutumien ja erkaantumisten analyysissä ovat identiteetin merkityksellistäminen ja kritiikki, sukupuolen ja seksuaalisuuden kategorioiden toisistaan erottamisen mahdottomuus, ja, lopulta kysymys siitä voidaanko feminismiä ja queeriäkään pitää erillään toisistaan. Pitäisikö niiden toisiinsa lomittuvan historian jälkeen jo puhua sekä queerfeminismistä että feministisestä queer-ajattelusta?
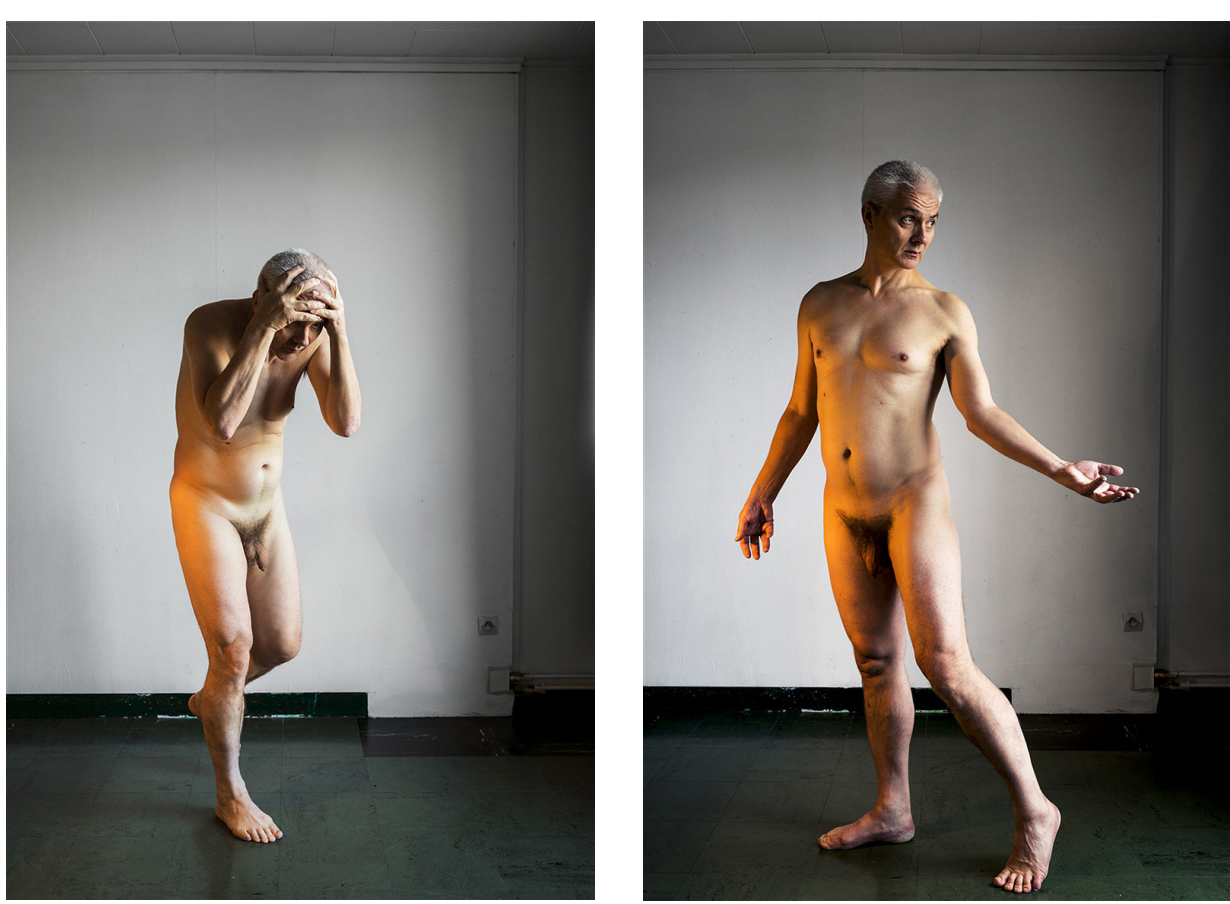

KUVAT:

Kari Soinio, Andrieu d'Andres I, Calais'n porvarit (Après de Rodin) / 2018 (Les Bourgeois de Calais, Auguste Rodin, 1884-1889)

Kari Soinio, Jean de Fiennes, Calais'n porvarit (Après de Rodin) / 2018 (Les Bourgeois de Calais, Auguste Rodin, 1884-1889).

Asta Kihlmanin artikkeli paikantuu paitsi queer-tutkimukseen myös taidehistoriaan. Artikkelissaan Kihlman esittää queer-luennan kolmen 1800-luvun lopulla ja 1900-luvun vaihteessa työskennelleen suomenruotsalaisen naisteilijan, Sigrid af Forsellesin, Ellen Thesleffin ja Beda Stjernschantzin tuotannosta. Psykoanalyyttisesti virittynyt teksti osallistuu

keskusteluun käsitteiden käytön historiallisuudesta ja siitä kuinka nykykäsitteet taipuvat vuosisatojen takaisten ilmiöiden tarkasteluun. Kihlman ehdottaa historiallisten taideteosten luennassaan minäkuvallisuus-termiä

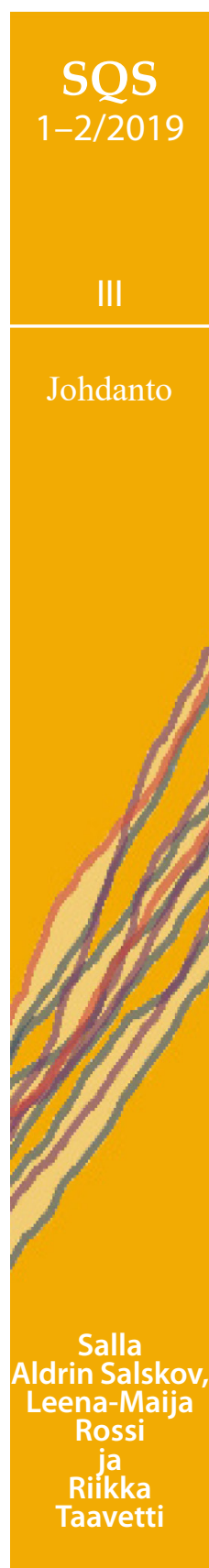


käsitteellistämään eräänlaista uudelleenajateltua subversiivista identiteettipolitiikkaa.

Identiteetin tarkastelu yhdistääkin kaikkia tämän numeron vertaisarvioituja artikkeleita, vaikka aiheen pohtiminen tapahtuukin hyvin erilaisista näkökulmista. Tämä on tutkimuksellisesti kiinnostavaa, sillä, kuten artikkeleistakin käy hyvin ilmi, identiteetti on ollut queer-tutkimuksen kentällä kenties kaikkein kiistanalaisin käsite. Sitä on kritisoitu muun muassa kategorisuudesta, normittavuudesta, ulossulkevuudesta ja essentialismista. Samalla identiteetti on kuitenkin säilynyt käsitteenä, jonka ympärille queer-tutkijat paikantavat itsensä yhä uudelleen, joko kriittisesti tai pyrkien löytämään sille mielekkäitä poliittisia käyttötapoja.

Taidehistorian lisäksi myös nykytaide on esillä tässä numerossa:”Pervolinssin" galleriavieraana on valokuvataiteilija Kari Soinio ja esseiden joukossa julkaisemme Heidi Lunabban sarjakuvakerrontaa. Soinio on kuvannut omaa ruumistaan outouttaen ja binaarinormistoa haastaen jo kolmen vuosikymmenen ajan. Hänen teostensa alaston "sankari" on saanut milloin feminiinisiä tai sukupuolten välille asettuvia piirteitä, milloin parodioinut hegemonisen maskuliinisuuden ideaaleja, milloin eläimellisesti kääntänyt nurin luonnon ja ihmisen hallintasuhdetta. Lunabba tunnetaan puolestaan installaatioistaan ja yhteisöllisistä teoksistaan, joissa hän on kutsunut osallistujia tutkimaan sukupuolen ja identiteetin kysymyksiä.

Ainoana suomalaisena queer-tutkimuslehtenä SQS on myös tärkeä areena tuoreen kotimaisen tutkimuksen käsittelyyn sekä erityisesti suomalaisille lukijoille kiinnostavan ulkomaisen tutkimuksen esittelyyn. Tämän numeron kirja-arvioissa esitellään Marie-Louise Holmin, Asta Kihlmanin sekä Riikka Taavetin väitöskirjat, jotka kaikki liittyvät queer-historialliseen tutkimukseen, eri näkökulmista ja eri tieteenaloilta.

\section{Kirjallisuus}

Hellesund, Tone. 2016. "Skeivt Arkiv: The Establishment of a Queer Historical Archive in Norway 2012-2015." Lambda Nordica (3-4): 111-134.

Kekki, Lasse. 2006. "Pervon puolustus". Kulttuurintutkimus 23 (2006): 3, 3-18.

Kornak, Jacek. 2015. Queer as a Political Concept. Helsinki: University of Helsinki.

de Lauretis, Teresa (toim.). 1991. Queer Theory: Lesbian and Gay Sexualities. differences 3(2), iii-xviii.

Mizielińska, Joanna. 2006. "Queering Moominland: The Problems of Translating Queer Theory into a Non-American Context.” SQS 1 (1): 87-104.

Mizielińska, Joanna ja Robert Kulpa. 2011. "'Contemporary Peripheries': Queer Studies, Circulation of Knowledge and East/West Divide. "Teoksessa De-Centring Western Sexualities: Central and Eastern European Perspectives, toimittaneet Robert Kulpa ja Joanna Mizielińska, 11-26. Farnham: Ashgate.

Rossi, Leena-Maija. 2017. Hauras, korjaava ja parantumaton queer - katse ylpeyden, normatiivisuuden ja (uus)häpeän aikoihin. $S Q S$ 11(1): 1-18. https://doi.org/10.23980/sqs.66351

Rossi, Leena-Maija. 2003. Heterotehdas: Televisiomainonta sukupuolituotantona. Helsinki: Gaudeamus.

Vänskä, Annamari. 2006. Vikuroivia vilkaisuja. Ruumis, sukupuoli, seksuaalisuus ja visuaalisen kulttuurin tutkimus. Taidehistoriallisia tutkimuksia 35. Taidehistorian seura: Helsinki.

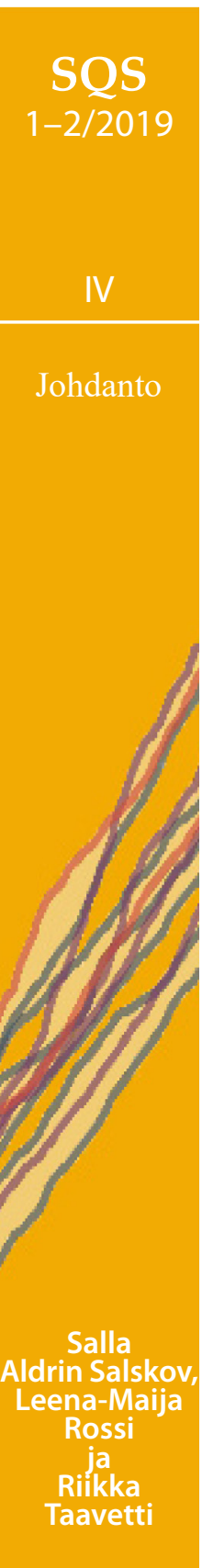

